\title{
Coronavirus Disease-2019 Survival in Mexico: A Cohort Study on the Interaction of the Associated Factors
}

\author{
Horacio Márquez-González ${ }^{1}$, Jorge F. Méndez-Galván², Alfonso Reyes-López ${ }^{3}$, \\ Miguel Klünder-Klünder ${ }^{4}$, Rodolfo Jiménez-Juárez ${ }^{5}$, Juan Garduño-Espinosa ${ }^{6}$ and \\ Fortino Solórzano-Santos ${ }^{7 *}$
}

\begin{abstract}
${ }^{1}$ Department of Clinical Research, Hospital Infantil de México Federico Gómez, Mexico City, Mexico, ${ }^{2}$ Centre for Research in Emerging Diseases, Hospital Infantil de México Federico Gómez, Mexico City, Mexico, ${ }^{3}$ Centre for Health Economics, Hospital Infantil de México Federico Gómez, Mexico City, Mexico, ${ }^{4}$ Research Management, Hospital Infantil de México Federico Gómez, Mexico City, Mexico, ${ }^{5}$ Clinical Infectious Disease Department, Hospital Infantil de México Federico Gómez, Mexico City, Mexico, ${ }^{6}$ Clinical Research Direction, Hospital Infantil de México Federico Gómez, Mexico City, Mexico, ${ }^{7}$ Infectious Diseases Research Department, Hospital Infantil de México Federico GómezMéxico Federico Gómez, Mexico City, Mexico
\end{abstract}

OPEN ACCESS

Edited by:

Burc Barin

Emmes Corporation, United States

Reviewed by:

Shirley Galbiati,

The Emmes Company, United States

Dayi Zhang,

Tsinghua University, China

${ }^{*}$ Correspondence: Fortino Solórzano-Santos solorzanof056@gmail.com

Specialty section:

This article was submitted to Infectious Diseases - Surveillance,

Prevention and Treatment, a section of the journal Frontiers in Public Health

Received: 29 January 2021 Accepted: 24 June 2021 Published: 27 July 2021

Citation:

Márquez-González $\mathrm{H}$, Méndez-Galván JF, Reyes-López A, Klünder-Klünder M, Jiménez-Juárez $R$,

Garduño-Espinosa J and

Solórzano-Santos F (2021) Coronavirus Disease-2019 Survival in

Mexico: A Cohort Study on the Interaction of the Associated Factors.

Front. Public Health 9:660114.

doi: 10.3389/fpubh.2021.660114
The pandemic caused by the new coronavirus Severe Acute Respiratory Syndrome Coronavirus-2 (SARS-CoV-2) is currently affecting more than 200 countries. The most lethal clinical presentation is respiratory insufficiency, requiring attention in intensive care units (ICU). The most susceptible people are over 60 years old with comorbidities. The health systems organization may represent a transcendental role in survival.

Objective: To analyze the correlation of sociodemographic factors, comorbidities and health system organization variables with survival in cases infected by SARS-CoV-2 during the first 7 months of the pandemic in Mexico.

Methods: The cohort study was performed in a health system public basis from March 1st to September 30th, 2020. The included subjects were positive for the SARS-CoV-2 test, and the target variable was mortality in 60 days. The risk variables studied were: age, sex, geographic distribution, comorbidities, health system, hospitalization, and access to ICU. Bivariate statistics ( $X^{2}$-test), calculation of fatality rates, survival analyses and adjustment of confusing variables with Cox proportional-hazards were performed.

Results: A total of 753,090 subjects were analyzed, of which the $52 \%$ were men. There were 78,492 deaths (10.3\% of general fatality and $43 \%$ inpatient). The variables associated with a higher risk of hospital mortality were age (from 60 years onwards), care in public sectors, geographic areas with higher numbers of infection and endotracheal intubation without management in the ICU.

Conclusions: The variables associated with a lower survival in cases affected by SARS-CoV-2 were age, comorbidities, and respiratory insufficiency (with endotracheal intubation without care in the ICU). Additionally, an interaction was observed between the geographic location and health sector where they were treated.

Keywords: Mexico, SARS-CoV-2, survival analysis, cohort study, comorbidity, COVID-19 outbreak 


\section{INTRODUCTION}

The Severe Acute Respiratory Syndrome Coronavirus-2 (SARS$\mathrm{CoV}-2$ ) outbreak has been declared as a pandemic by the World Health Organization. The first case of this disease in Mexico was reported on April 28th, 2020. Until April 1, 2021, 131,435,555 cases of Coronavirus Disease-2019 (COVID-19) were registered worldwide, with a global fatality rate of $2.17 \%$ (1). At that time, 2,443,755 cases and 204,147 deaths were confirmed in Mexico, with a fatality rate of $9 \%$ (2). The disease is highly contagious, and although fatality remains low, there is a constant increase in the number of new cases in Mexico with a higher fatality rate than that observed globally (1).

Several changes in some epidemiological indicators have been observed worldwide: according to the initial findings in China, it was indicated that older adults presented more severe symptoms. In Europe, the population over 60 years old was the most affected, which coincide with being the community with the highest life expectancy in the world (3-6). In Latin-America, COVID-19 is also frequently observed in the population under 60 years of age, whereas in Brazil, $47 \%$ of cases occur between 20 and 59 years of age, and this was associated with the presence of comorbidities such as obesity, diabetes and hypertension, which are frequent at early ages (6-9). There is no specific treatment so far; a decrease in SARS-CoV-2 fatality cases was achieved with an appropriate care, including prompt hospitalization, mechanical ventilation, and attention in an intensive care unit $(10,11)$.

The hospital reconversion in Mexico and other countries has enabled an increase in resources (more hospitals, ventilators, and intensive care units (ICU) for patients with acute and severe COVID-19. According to daily reports in Mexico, there was an increase in the number of ICU beds or "beds with ventilators" from 2,446 to 11,346 over a 10-month period (12). However, the changes in fatality rates were not substantial (12). A hypothesis derived from early assessments showed that comorbidities in the Mexican population have a negative impact on survival, especially in cases of diabetes, arterial hypertension, and obesity $(13,14)$. In addition, there are other related conditions to death, such as the hospital's number and the health services quality that are variously distributed in the country. These variables must be weighted to identify the riskiest conditions. The experience in the results presented in Mexico may be helpful for other countries with similar social, economic and health system conditions, for a better chance in their public health strategies.

The aim of this study was to analyze the survival of confirmed cases with SARS-CoV-2 in the first 7 months of the national pandemic, assessing the impact of different factors as age, sex, comorbidities, healthcare system organization, medical unit geographic location, modality of care received, and access to ICU.

\footnotetext{
Abbreviations: CDMX, City of Mexico; COVID-19, Coronavirus Disease-2019; EDOMEX, State of Mexico; ICU, intensive care unit; IMSS, Instituto Mexicano de Seguridad Social; IMV, invasive mechanical ventilation; ISSSTE, Instituto de Seguridad y Servicios Sociales de los Trabajadores del Estado; PEMEX, Petroleos de México; SARS-CoV-2, Severe Acute Respiratory Syndrome Coronavirus-2; SEDENA, Secretaría de la Defensa Nacional; SEMAR, Secretaría de la Marina; SS, Secretaría de Salud.
}

\section{MATERIALS AND METHODS}

The data used was from the open database of the Viral Respiratory Disease Epidemiological Surveillance Systems published daily by the Ministry of Health of Mexico (2). Among the variables available in the databases, the type of institution of the National Health System that provided care, federative entity where the medical unit was located, type of care (ambulatory, hospitalized), date of admission, gender, age, place of residence, date of symptoms onset, intubated or inpatient in ICU, presence of comorbidities, smoking history, pregnancy, and date of death if occurred were included. The confirmation of SARS-CoV-2 infection was performed by real-time polymerase chain reaction technique in certified laboratories by the National Institute of Epidemiological Reference.

A cohort of patients with positive SARS-CoV-2 test result was integrated from February 28th to September 30th, 2020. The day 0 of every patient was considered as the disease confirmation date and tracking was done till day 60 or the date death. The exposition variables were age (categorized in groups: $<2,2.1-5,6-10,11-20,21-30,31-40,41-50,51-60,61-$ $70,71-80$, and $>80$ years), sex, federative entity (32 States of Mexico). The following comorbidities were registered: obesity, diabetes, arterial hypertension, asthma or chronic obstructive pulmonary disease (COPD), immunosuppression and other risk factors such as smoking and pregnancy. Main health institutions of the country were analyzed: private institutions, Secretaría de Salud (SS), Instituto Mexicano de Seguridad Social (IMSS), Instituto de Seguridad y Servicios Sociales de los Trabajadores del Estado (ISSSTE), Petroleos de México (PEMEX), Secretaría de la Marina (SEMAR), Secretaría de la Defensa Nacional (SEDENA), State Hospitals, and the group of "other public" that assist $<2 \%$ of the population. The outcome variables also included were: hospitalization, pneumonia, invasive mechanical ventilation (IMV), and admission to ICU. The main outcome variable was survival till 60 days.

\section{Statistical Analysis}

Descriptive statistical analyses of the variables of interest were performed by calculating the relative frequencies, and independent hypothesis tests $\left(X^{2}\right)$ were used to assess correlations between qualitative variables. The softened risk density in patients hospitalized vs. those in ambulatory care was analyzed using Nelson-Aalen estimation (Supplementary Material). The analyses of survival were performed using Kaplan-Meier method with the log rank test. Finally, different models of Cox regression were constructed to evaluate the effect of the different clinical, demographic, and socio-economic factors on the period of death. The criteria for introducing the model were $p$-value $<0.05$ or biological plausibility. Finally, three different models were built: the total population, hospitalized patients, and the ICU. Internal validation of each model was performed by calculating each patient's probability in the cohort with the formula, $\lambda(t)=\lambda_{0}(t) \exp \left(\beta^{T} X\right)$, and estimating the value of the area under the curve (AUC) with the death variable (15). The entire analysis was performed using the Stata 16.1 version. 

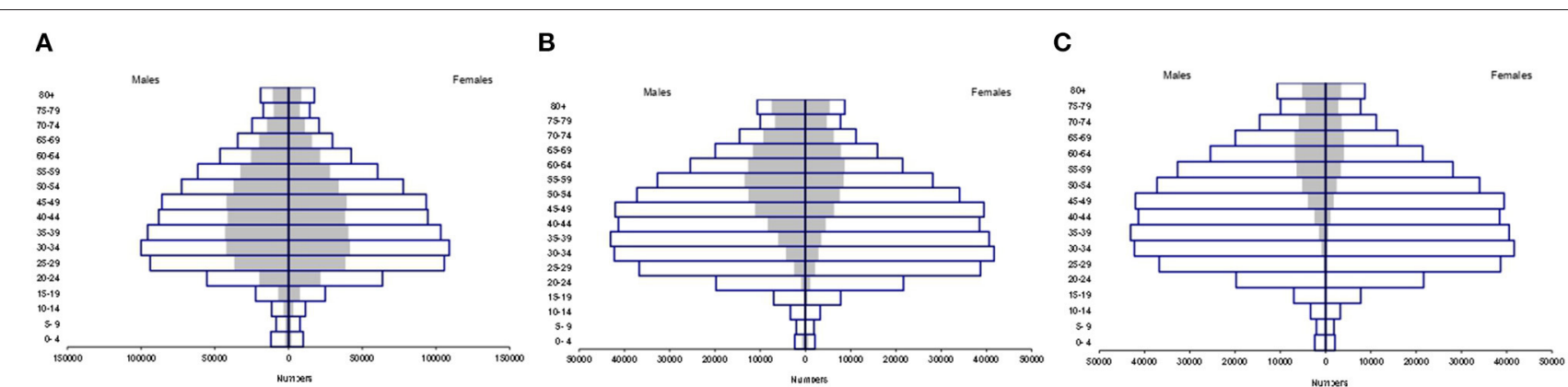

FIGURE 1 | Distribution according to age group and sex, in Mexico. (A) Distribution of suspected cases (white bar) and positive cases (gray bar) according to age group and sex, in Mexico. (B) Distribution of positive cases (white bar) and hospitalized cases (gray bar) according to age group and sex, in Mexico. (C) Distribution of patients who died from SARS Cov-2 by age group and sex in Mexico. Positive cases (white bar) and deaths (gray bar).

\section{RESULTS}

A total of $1,735,597$ observations were included in the original basis, of which were eliminated for analysis 893,324 (51.5\%) who corresponded to patients with negative SARS-CoV-2 test, and 89,186 (5.1\%) individuals whose results were not available.

Analysis was made with 753,090 patients with positive SARSCoV-2 test, $52 \%$ were males, and $>55 \%$ of the population was grouped between 20 and 59 years old (Figure 1A). Male sex was predominant in all age groups requiring hospitalization. Both men $(70.2 \%)$ and women $(61.5 \%)$ aged $>80$ years required a higher proportion of hospitalizations. The lowest hospitalization proportion was observed in younger people (15-24 years old group), Figure 1B.

A total of 78,534 deaths were registered. The lowest fatality rate was observed in people $<18$ years of age $(0.86 \%)$, followed in ascending order by patients of age groups 19-40 (7.03\%), 40-60 $(35.9 \%)$, and $>60(56.1 \%)$, the male population being the most predominant (Figure 1C).

Patients $<18$ years of age had a lower percentage of comorbidities, and $14 \%$ of infected children had one comorbidity. The comorbidities observed in the descending order of frequency were obesity (3.7\%), asthma (3.7\%), immunosuppression (2.9\%), diabetes mellitus (0.7\%), arterial hypertension (0.7\%), and chronic renal failure $(0.7 \%)$. The greater comorbidities frequencies were observed in children of 11-18 years old; obesity (6\%), asthma (4\%), and immunosuppression (1.5\%) were highlighted. It must be noted that $4.7 \%$ of infected people $<18$ years of age were obese and represented $0.8 \%$ of the total obese population infected with SARS-CoV-2 (Table 1).

The principal comorbidities observed among people aged $\geq 19$ years included arterial hypertension (20\%) and obesity (19\%) followed by diabetes mellitus (16\%), asthma (2.6\%), chronic renal failure (1.9\%), and immunosuppression (1\%) in the descending order of frequency. The largest number of patients with some comorbidity is grouped between 19 to 60 years of age (Table 1).

A significant statistical difference was observed between the proportions of comorbidities in the group of non-surviving and surviving patients (Table 2 ). Higher fatality rates could be found in the age group of $>60$ years. Further, the high frequency of comorbidities in the age group of 40-60 years is of concern.

According to geographical distribution (Table 3), a large number of positive cases and deaths were concentrated in Mexico City (CDMX) and Mexico State (EDOMEX), which are states with the largest population in our country. The national case fatality rate was $10.4 \%$, whereas that in CDMX and EDOMEX was 7.98 and $16.2 \%$, respectively.

Some entities with lower population density showed greater case fatality rates, such as the States of Morelos, Baja California, Sinaloa, Chiapas, and Hidalgo. In other states, population density was not associated with case fatality rate.

$23.8 \%$ of positive SARS-Cov-2 patients required hospitalization of which $17.5 \%$ received endotracheal intubation and $8.6 \%$ were admitted in an ICU. The proportion of patients who required endotracheal intubation and who could be attended to in an ICU was variable in different states; however, the case fatality rate was higher in those states with a higher rate of intubated patients with lower admissions in ICU than others.

In study period $23.8 \%(179,288)$ of the patients with SARSCoV-2 infection were hospitalized (Table 4); among these, $76.8 \%$ had pneumonia as the main diagnosis, $20.1 \%$ required intubation and $8.6 \%$ was inpatient in an ICU. Nationally, $89.3 \%$ of the cases were attended in three institutions: IMSS (48.1\%), SS (33.6\%) and ISSSTE (7.6\%). The institutional case fatality rate (CFR) was $43.7 \%$. Among the patients admitted to IMSS, $30 \%$ had pneumonia, $10.9 \%$ who were intubated required IMV, and $2 \%$ were attended to in an ICU. Among patients admitted at SS, $30.8 \%$ had pneumonia, $6.2 \%$ required IMV, and $4.8 \%$ were treated in an ICU. Private hospitals attended to $2.1 \%$ of hospitalized patients with COVID-19. Among these, 22\% required IMV and $27 \%$ were admitted in an ICU. The CFRs for IMSS, SS, and private hospitals were 50.7, 39.2, and $19.4 \%$, respectively.

Other's health system hospitals where ICU attention was greater were SEDENA (29.9\%), private hospitals $(27.2 \%)$, and SEMAR (24.1\%). These units had lower CFR, 14.9, 4.3, and $7.1 \%$, respectively.

In non-hospitalized patients, the survival at 60 days was 95.4\%; in contrast survival in hospitalized patients was $75 \%$, with an survival average of 11 days $(p<0.05)$ (Figure $2 \mathrm{~A}$ ). 


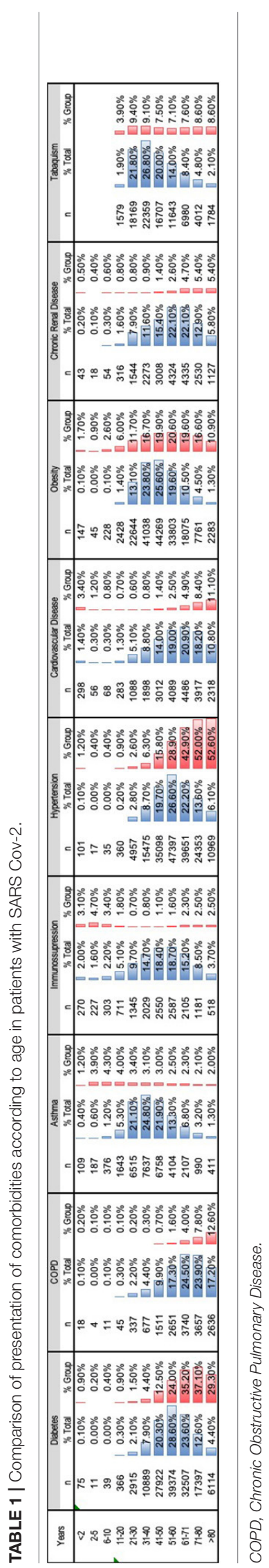

In addition, in hospitalized patients, there was a direct association between age and survival $(p<0.05)$ (Figure 2B). Patient survival was higher (average: 33 days) among those hospitalized in private than in public institutions. Lower survival (average: 10 days) was observed in patients admitted to IMSS (Figure 2C).

On comparing the probability of survival based on the number of comorbidities, patients with three or more comorbidities were found to have a lower probability of survival (Figure 2D).

The adjustment of the effect of the variables with mortality was performed using three Cox proportional models (Table 5). The individual probability of outcome presentation by each subject according to each model was calculated. In the first prognostic model, the mortality of all subjects was explained, including all variables with a $p$-value $<0.05$ (sex, age group, health service, comorbidities, the need for hospitalization, and pneumonia), resulting in 10 associated variables, two related to the health system (private practice with protective effect), five comorbidities and their sum, pneumonia development, and need for hospitalization. The summed probability of the model showed an area under the curve (AUC) of 0.86 .

The second model variables (sex, age $>60$ years, type of health service, comorbidities, ICU, and IMV) were adjusted in hospitalized patients and demonstrated the association of 12 variables, which differed from model 1 and additionally included the following: age $>60$ years, male, asthma, smoking, and pregnancy. In terms of independent care in the ICU and AMV, the variables demonstrated an association with the risk of death; however, the combination of both offered a protective effect. The AUC value was determined as 0.78 .

The last model was carried out in ICU patients, demonstrating a primary association between the type of health services and comorbidities. The AUC value was observed to be 0.65 .

\section{DISCUSSION}

We have provided an analysis of the first 7 months from the start of the COVID-19 pandemic in Mexico. CFR has been considered higher for Mexico compared with many other countries. However, during the first 3 months of the pandemic, sampling of the people suspected to have SARSCov-2 virus was limited; "sentinel monitoring" was used (only one in every 10 suspected ambulatory cases and all hospitalized cases were sampled). Therefore, CFR denominator was underestimated (diagnosis confirmation bias). The number of samples gradually increased and included all clinically suspected patients. Only 14 tests per 1,000 people were carried out in Mexico, which was in contrast to that observed in a study carried out in Chile, where 130 PCR tests were carried out per 1,000 people, obtaining a fatality rate of $4.16 \%(16)$.

Considering the COVID-19 registered deaths around the world, Mexico is placed as the 3th country of the world with major number of deaths, behind the United States and Brazil 
TABLE 2 | Differences between survivors and non-survivors with SARS CoV-2.

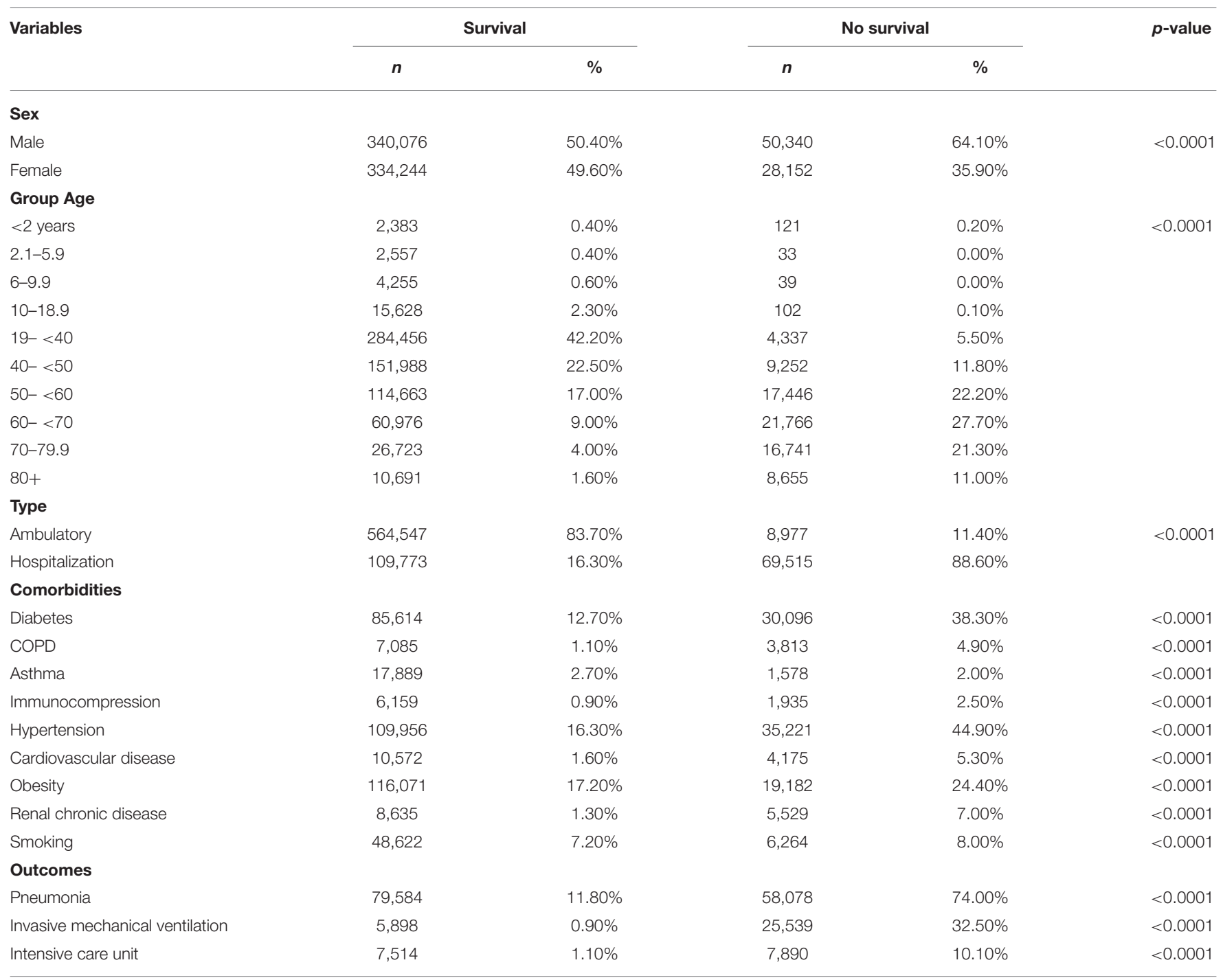

The value of $p$ was calculated by $X^{2}$ test.

(1). Age has been considered one of the most outstanding death risk factors in most countries of the world. The percentage of deaths in the first wave in people over 60 years of age in Italy and China were 96.5 and $81 \%$, respectively. A total of $98 \%$ of the deceased were older than 50 years in England, 97.5\% were older than 45 years in USA, and $56.2 \%$ were over 60 years of age in Mexico $(5,17,18)$. It is of interest that $19.5 \%$ of the deceased individuals in Mexico were between 21 and 50 years of age, which corresponds to a young and economically active population. In Mexico, a mandatory lockdown was not imposed, and Mexican population with low and middle income, has no savings capacity; hence, people had the necessity to work, this factor could influence on the higher disease incidence and higher mortality rates observed in young people with risk factors for developing a serious disease (13, 14).
In our country infected patients aged $<20$ years represented $3.1 \%$ of the total infected population; the CFR was $0.12 \%$, which was similar to that observed in Spain, Italy, Germany, China, and South Korea $(19,20)$. The number of infected children in Mexico has been strikingly higher than that in countries. Little is known about COVID-19 and comorbidities in children (21). In the infected Mexican population aged $<18$ years, the percentage of comorbidities was low (14\%); obesity $(4.7 \%)$ and diabetes mellitus $(0.8 \%)$ were not factors with a high incidence, which was in contrast to that observed in the adult population. Comorbidities were most frequent in children aged 11-18 years. Most of the Mexican children did not have any comorbidity. A Saudi Arabian cohort, which included population aged $<1$ and $>5$ years, was observed to have a high rate of hospitalization, with a low percentage of comorbidities (22). 
TABLE 3 | Hospitalization, ICU care, endotracheal intubation, and fatality by State.

\begin{tabular}{|c|c|c|c|c|c|c|c|c|c|c|}
\hline & $\begin{array}{c}\text { Positive SARS } \\
\text { CoV-2 }\end{array}$ & Hospitalizated & $\begin{array}{l}\text { Endotracheal } \\
\text { Intubation }\end{array}$ & $\%$ & ICU & $\%$ & Death & $\begin{array}{l}\% \text { by } \\
\text { State }\end{array}$ & $\%$ total & $\begin{array}{c}\text { Fatality rate } \\
\text { (x100) }\end{array}$ \\
\hline Ags & 7429 & 2008 & 392 & 19.52 & 72 & 3.59 & 663 & 33.02 & 0.37 & 8.92 \\
\hline B.C.N & 19421 & 6512 & 1365 & 20.96 & 243 & 3.73 & 3552 & 54.55 & $\square 1.98$ & 18.29 \\
\hline B.C.S & 10393 & 1197 & 287 & 23.98 & 171 & 14.29 & 478 & 39.93 & 0.27 & 4.60 \\
\hline Camp & 6116 & 1854 & 256 & 13.81 & 243 & 13.11 & 829 & 44.71 & 0.46 & 13.55 \\
\hline Coah & 26800 & 3910 & 591 & 15.12 & 138 & 3.53 & 1911 & 48.87 & 1.07 & 7.13 \\
\hline Col & 5152 & 1486 & 354 & 23.82 & 196 & 13.19 & 579 & 38.96 & 0.32 & 11.24 \\
\hline Chis & 6233 & 2249 & 577 & 25.66 & 246 & 10.94 & 1020 & 45.35 & 0.57 & 16.36 \\
\hline Chih & 11449 & 3344 & 715 & 21.38 & 779 & 23.30 & 1397 & 41.78 & 0.78 & 12.20 \\
\hline Cd.Mx & 153255 & 28134 & 6969 & 24.77 & 2576 & 9.16 & 12224 & 43.45 & 6.82 & 7.98 \\
\hline Dgo & 9133 & 1322 & 258 & 19.52 & 193 & 14.60 & 639 & 48.34 & 0.36 & 7.00 \\
\hline Gto & 41366 & 6313 & 793 & 12.56 & 499 & $\square .90$ & 2953 & 46.78 & $\square 1.65$ & 7.14 \\
\hline Gro & 18962 & 3989 & 893 & 22.39 & 621 & 15.57 & 1899 & 47.61 & 1.06 & 10.01 \\
\hline Hgo & 12517 & 4430 & 499 & 11.26 & 281 & $\square 6.34$ & 1998 & 45.10 & 1.11 & 15.96 \\
\hline Jal & 27467 & 8095 & 1314 & 16.23 & 875 & 10.81 & 3332 & 41.16 & $\square 1.86$ & 12.13 \\
\hline Edo Mex & 58490 & 25265 & 3916 & 15.50 & 990 & 3.92 & 9496 & 37.59 & 5.30 & 16.24 \\
\hline Mich & 20677 & 3866 & 575 & 14.87 & 244 & $\square .31$ & 1653 & 42.76 & 0.92 & 7.99 \\
\hline Mor & 5665 & 2543 & 329 & 12.94 & 105 & प 4.13 & 1102 & 43.33 & 0.61 & 19.45 \\
\hline Nay & 5948 & 1933 & 259 & 13.40 & 208 & 10.76 & 745 & 38.54 & 0.42 & 12.53 \\
\hline N.L & 41172 & 8249 & 1069 & 12.96 & 902 & 10.93 & 3148 & 38.16 & $\square 1.76$ & 7.65 \\
\hline Oax & 16999 & 3340 & 706 & 21.14 & 436 & 13.05 & 1421 & 42.54 & 0.79 & 8.36 \\
\hline Pue & 32398 & 9237 & 1271 & 13.76 & 779 & 8.43 & 4115 & 44.55 & 2.30 & 12.70 \\
\hline Que & 9546 & 2781 & 643 & 23.12 & 150 & 5.39 & 999 & 35.92 & 0.56 & 10.47 \\
\hline Q.Roo & 11888 & 3423 & 920 & 26.88 & 391 & 11.42 & 1659 & 48.47 & 0.93 & 13.96 \\
\hline S.L.P & 23407 & 3444 & 421 & 12.22 & 323 & 9.38 & 1712 & 49.71 & 0.95 & 7.31 \\
\hline $\operatorname{Sin}$ & 18904 & 6473 & 1201 & 18.55 & 877 & 13.55 & 3218 & 49.71 & $\square 1.79$ & 17.02 \\
\hline Son & 24874 & 5866 & 979 & 16.69 & 290 & 4.94 & 2914 & 49.68 & $\square 1.63$ & 11.72 \\
\hline Tab & 32341 & 4675 & 515 & 11.02 & 417 & $\square .92$ & 2838 & 60.71 & $\square 1.58$ & 8.78 \\
\hline Tam & 29084 & 4478 & 490 & 10.94 & 225 & 5.02 & 2281 & 50.94 & $\square 1.27$ & 7.84 \\
\hline Tlax & 6584 & 1920 & 380 & 19.79 & 552 & 28.75 & 1029 & 53.59 & 0.57 & 15.63 \\
\hline Ver & 33005 & 11239 & 1676 & 14.91 & 865 & 7.70 & 4333 & 38.55 & 2.42 & 13.13 \\
\hline Yuc & 18630 & 4015 & 560 & 13.95 & 234 & 5.83 & 1633 & 40.67 & 0.91 & 8.77 \\
\hline $\mathrm{Zac}$ & 7507 & 1698 & 264 & 15.55 & 283 & 16.67 & 722 & 42.52 & 0.40 & 9.62 \\
\hline Total & 752812 & 179288 & 31437 & 17.53 & 15404 & 8.59 & 78492 & 43.78 & & 10.43 \\
\hline
\end{tabular}

Ags, Aguascalientes; B.C.N, Baja California Norte; B.C.S, Baja California Sur; Camp, Campeche; Coah, Coahuila; Col, Colima; Chis, Chiapas; Chih, Chihuahua; Cd.Mx, Ciudad de México; Dgo, Durango; Gto, Guanajuato; Hgo, Hidalgo; Jal, Jalisco; Edo Mex, Estado de México; Mich, Michoacán; Mor, Morelos; Nay, Nayarit; N.L, Nuevo León; Oax, Oaxaca; Pue, Puebla; Que, Querétaro; Q.Roo, Quintana Roo; S.L.P, San Luis Potosí; Sin, Sinaloa; Son, Sonora; Tab, Tabasco; Tam, Tamaulipas; Tlax, Tlaxcala; Ver, Veracruz; Yuc, Yucatán; Zac, Zacatecas. 


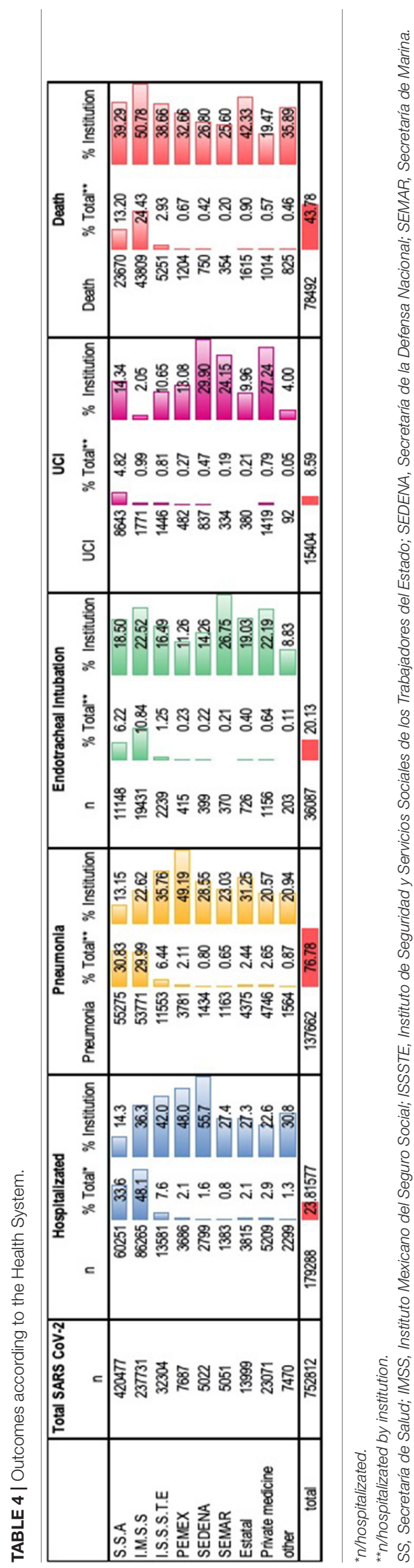

There was a relationship in mortality between the economic States conditions and the health services distribution; for example, difference in the fatality rate was twice higher in the Edo Mex than in the $\mathrm{Cd} \mathrm{Mx}$ despite that Edo Mex population is twice as high $(16,992,418$ vs. 9,209,944 people) (23), but the gross domestic product is $45 \%$ lower in Edo Mex, a condition reflected in the provision of health services; in $\mathrm{Cd} \mathrm{Mx}$ the number of third level hospitals is 3.5 higher (56 vs. 16 hospital centers) (24). The impact of sociodemographic conditions on mortality in Brazil was evaluated by Braga-Ribeiro et al., who found an association between less education, more household crowding, lower income, and a higher population concentration in subnormal areas; mortality was found to be four times higher in a population with a lower degree of education compared with that having a higher degree of education, showing that socio-economic inequity impacts fatality during this pandemic (25).

Nation-wide, the proportion of confirmed cases that required hospitalization was $23.8 \%, 17.5 \%$ were intubated and $8.6 \%$ were inpatient in an ICU and $43.8 \%$ of hospitalized patients died with a CFR of $10.4 \%$. A total of $50 \%$ of patients requiring endotracheal intubation received management outside an ICU; fatality was higher in such individuals than in than those who received attention in an ICU. There was variation according to every state, for example, in Baja California, 33\% of the confirmed cases were hospitalized and $20.9 \%$ of these were intubated, but only $3.7 \%$ were admitted in an ICU. In this state, the CFR was $18.3 \%$. In contrast Chihuahua, where $29 \%$ of the cases were hospitalized, $23.3 \%$ were admitted to an ICU, and $21.4 \%$ received attention outside an ICU, the CFR was $12.2 \%$. In the analysis by Health Institutions, the differences between the two institutions that serve the largest proportion of the national population stand out; $10 \%$ of admitted patients required endotracheal intubation and $2 \%$ were treated in an ICU in the IMSS, which had a fatality rate of $19 \%$, whereas $15 \%$ of admitted patients required endotracheal intubation and $14 \%$ were treated in an ICU at the SSA, which had a $6 \%$ fatality rate. Despite the fact that with health system policies there was an increase in the number of hospital beds and ventilators, the fatality rate in critically ill patients requiring endotracheal intubation was high, as observed in a previous study. This suggests that the quality of care was inadequate due to the lack of expertise of the medical and paramedical groups in ventilatory management and critical care medicine; however, expertise has improved as the pandemic progresses. Having only a sufficient number of beds with ventilators does not ensure optimal care or a better prognosis for patients with acute respiratory distress syndrome due to SARS-CoV-2. In this analysis, critical patients cared in ICU were not observed to be at higher risk of death vs. those who were intubated outside of an ICU, revealing infrastructure and specialized staff importance in care of such patients.

In this study due to the database characteristics, the period of disease progression and clinical conditions at the time of requesting medical care cannot be correlated, as well as the time interval between endotracheal intubation and displacement to ICU. In two studies in Mexico on patients receiving ICU care, the average time between the onset of symptoms and the inpatient 


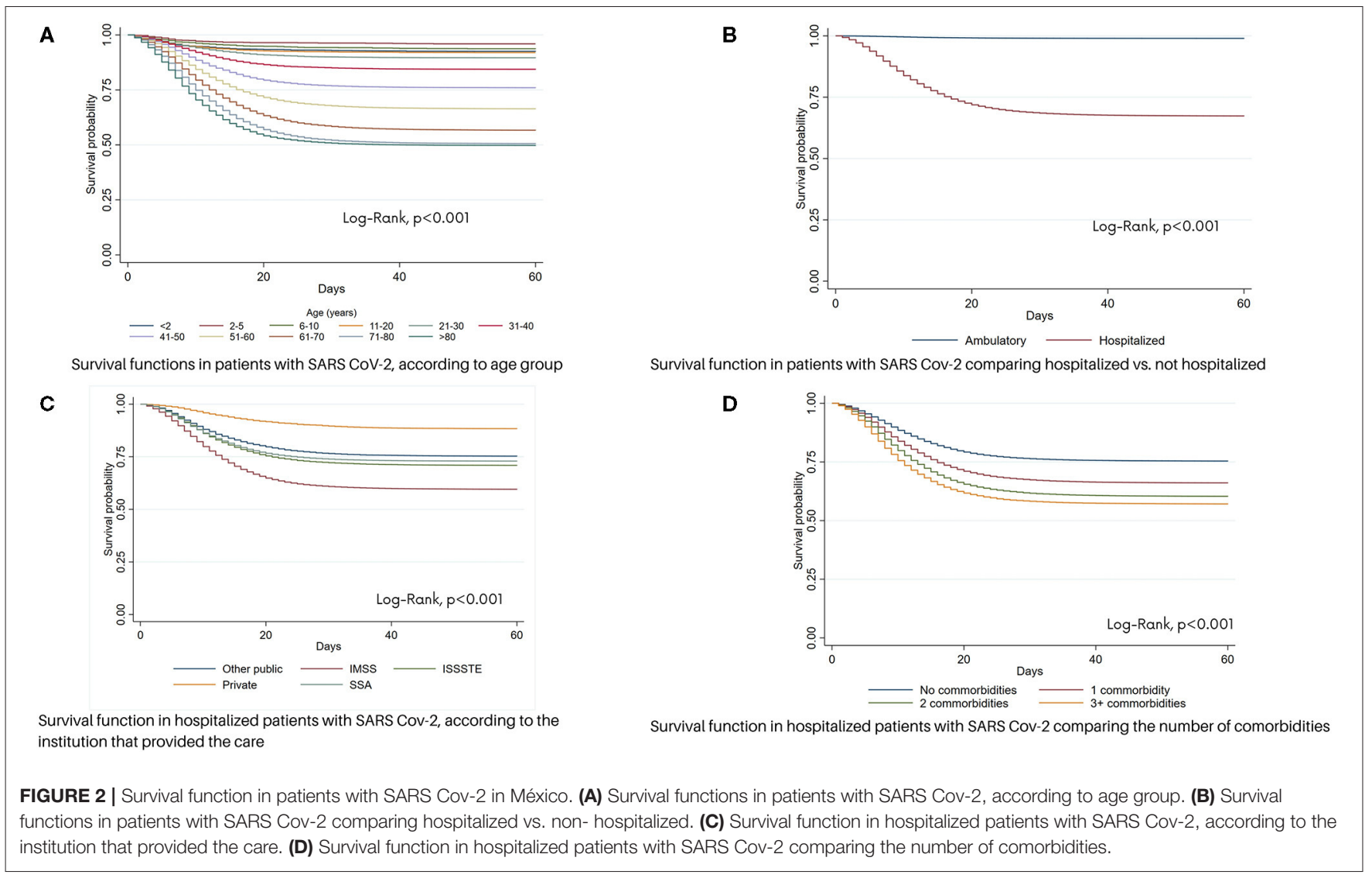

hospitalization in ICU was 7 days (interquartile range 4.5-9), the mean of days from the presentation of symptoms to admission was $4.3 \pm 3.4$ days; from the admission to death was $5.9 \pm 4.9$ days; and from the presentation of symptoms to death was 10.1 \pm 5.5 days $(12,13)$. There were $4.6 \%$ of non-hospitalized patients who died, which probably reflects health system problems during hospital service saturation and the low capacity of patients to recognize the severity of their condition and visit the hospital in a timely manner. The information collected however, was insufficient to delve into this topic.

The national database has been analyzed in other publications $(13,26)$. The three prognostic models presented in this work analyze the effect that risk variables have in different scenarios, particularly in patients in ICU; the analysis of Namendys Silva is consistent (12), who analyzed the decision made by the health authorities in Mexico during the second wave of infections, in December 2020, when the number of beds with a ventilator increased by 4.7 times (from 2,446 to 11,634) in hospital areas not equipped with intensive care, consequently, mortality was $12 \%$ higher, probably explained by human resources and the equipment had a lower quality of care. A recently published analysis in the pediatric population demonstrated the relationship among age, the clinical presentation with intubation, and the need for intubation as the variables associated with mortality (27).
Some limitations of this study include the following: (a) As each hospital center feeds the database and the results are issued as cases are added, reports on the outcomes are subject to the data being updated. Hence, it is possible that the population at cut-time may be underrated (follow-up bias); (b) Variables that assess the presence of comorbidities were obtained from questioning, and because the operational variables were not defined, a bias is highly probable (misclassification bias); (c) As hospitals followed a conversion strategy by using certain hospital areas as intensive care units, it is possible that the patients treated at this sites have been registered as intubated without ICU (registration bias); and (d) the construction of predictive models, using the PRISMA recommendations, shows that the variables analyzed could be insufficient to explain mortality fully. It is necessary to consider that, in the context of hospitalized patients, multiple variables that could be associated are involved (reporting bias).

\section{CONCLUSION}

In Mexico, mortality from SARS-CoV-2 was found to be associated with age and a history of comorbidities. The provision of services in the public sector is associated with mortality due to the relationship between IMV and access to intensive care areas. 
TABLE 5 | Proportional Cox Regression for prognostic mortality in patients with SARS CoV-2.

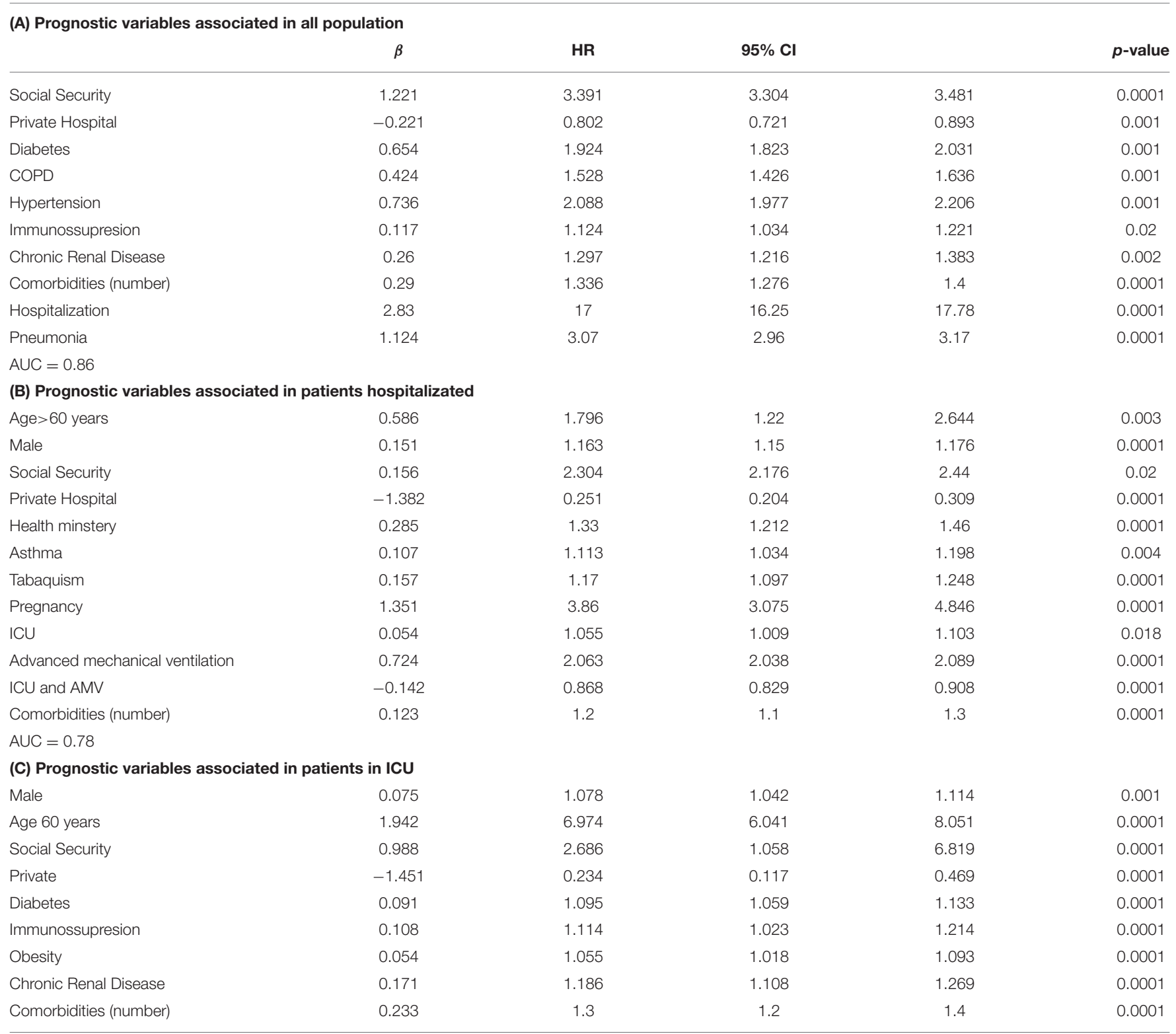

$A \cup C=0.65 ; \beta$, beta coefficient; $\mathrm{Cl}$, Confidence Interval; HR, Hazard Ratio.

\section{DATA AVAILABILITY STATEMENT}

The datasets presented in this study can be found in online repositories. The names of the repository/repositories and accession number(s) can be found in the article/Supplementary Material.

\section{ETHICS STATEMENT}

Ethical review and approval was not required for the study on human participants in accordance with the local legislation and institutional requirements. Written informed consent was not provided because Research subjects were obtained from the public database of the Secretariat of Health of Mexico. Access to the identity of the research subjects is not possible.

\section{AUTHOR CONTRIBUTIONS}

All authors contributed to the article and approved the submitted version. Analysis: HM-G, AR-L, MK-K, and FS-S. Manuscript writing: HM-G, JFM-G, MK-K, RJ-J, JG-E, and FS-S.

\section{SUPPLEMENTARY MATERIAL}

The Supplementary Material for this article can be found online at: https://www.frontiersin.org/articles/10.3389/fpubh. 2021.660114/full\#supplementary-material 


\section{REFERENCES}

1. John Hopkins University Medicine. COVID-19 Dashboard by the Center for Systems Science and Engineering (CSSE) at Johns Hopkins University. (2021). Available online at: https://coronavirus.jhu.edu/map.html (accessed May 31, 2021).

2. CONACYT. Covid-19 México. Información General. (2021). Available online at: https://datos.covid-19.conacyt.mx/ (accessed May 31, 2021).

3. Onder G, Rezza G. Brusaferro S. Case-fatality rate and characteristics of patients dying in relation to COVID-19 in Italy. J Am Med Assoc. (2020) 323:1775-76. doi: 10.1001/jama.2020.4683

4. Porcheddu R, Serra C, Kelvin D, Kelvin N. Rubino S. Similarity in case fatality rates (CFR) of COVID-19/SARS-COV-2 in Italy and China. J Infect Dev Ctries. (2020) 14:125-28. doi: 10.3855/jidc. 12600

5. Posso M, Comas M, Roman M, Domingo L, Louro J, González C, et al. Comorbidities and mortality in patients with COVID-19 aged 60 years and older in a University Hospital in Spain. Arch Bronconeumol. (2020) 56:75658. doi: 10.1016/j.arbr.2020.06.010

6. Wang D, Hu B, Hu C, Zhu F, Liu X, Zhang J, et al. Clinical characteristics of 138 hospitalized patients with 2019 novel coronavirusinfected pneumonia in Wuhan, China. J Am Med Assoc. (2020) 323:106169. doi: 10.1001/jama.2020.1585

7. Marson FAL, Ortega MM. COVID-19 in Brazil. Pulmonology. (2020) 26:24144. doi: 10.1016/j.pulmoe.2020.04.008

8. Mendizabal M, Pinero F, Ridruejo E, Anders M, Dolores Silveyra M, Torre A, et al. Prospective Latin American cohort evaluating outcomes of patients with COVID-19 and abnormal liver tests on admission. Ann Hepatol. (2021) 21:100298. doi: 10.1016/j.aohep.2020.100298

9. Ranzani OT, Bastos LSL, Gelli JGM, Marchesi JF, Baião F, Hamacher S, et al. Characterisation of the first 250,000 hospital admissions for COVID-19 in Brazil: a retrospective analysis of nationwide data. Lancet Respir Med. (2021) 9:407-18. doi: 10.1016/S2213-2600(20)30560-9

10. Cunningham AC, Goh HP, Koh D. Treatment of COVID-19: old tricks for new challenges. Crit Care. (2020) 24:91. doi: 10.1186/s13054-020-2818-6

11. Wang T, Du Z, Zhu F, Cao Z, An Y, Gao Y, et al. Comorbidities and multi-organ injuries in the treatment of COVID-19. Lancet. (2020) 395:e52. doi: 10.1016/S0140-6736(20)30558-4

12. Namendys-Silva SA. Case fatality ratio of COVID-19 patients requiring invasive mechanical ventilation in Mexico: an analysis of nationwide data. Crit Care. (2021) 25:68. doi: 10.1186/s13054-021-03485-w

13. Carrillo-Vega MF, Salinas-Escudero G, Garcia-Pena C, GutierrezRobledo LM. Parra-Rodriguez L. Early estimation of the risk factors for hospitalization and mortality by COVID-19 in Mexico. PLoS ONE. (2020) 15:e0238905. doi: 10.1371/journal.pone.0238905

14. Suarez V, Suarez Quezada M, Oros Ruiz S, Ronquillo De Jesus E. Epidemiology of COVID-19 in Mexico: from the 27th of February to the 30th of April 2020. Rev Clin Esp. (2020) 220:463-71. doi: 10.1016/j.rceng.2020.05.008

15. Royston P, Altman DG. External validation of a Cox prognostic model: principles and methods. BMC Med Res Methodol. (2013) 13:33. doi: 10.1186/1471-2288-13-33

16. Undurraga EA, Chowell G, Mizumoto K. COVID-19 case fatality risk by age and gender in a high testing setting in Latin America: Chile, March-August 2020. Infect Dis Poverty. (2021) 10:11. doi: 10.1186/s40249-020-00785-1

17. Merchant HA, Kow CS, Hasan SS. COVID-19 first anniversary review of cases, hospitalization, and mortality in the UK. Expert Rev Respir Med. (2021) 10:1890035. doi: $10.1080 / 17476348.2021 .1890035$
18. National Center for Health Statistics CfDCaP. Weekly Updates by Select Demographic and Geographic Characteristics. Provisional Death Counts for Coronavirus Disease 2019 (COVID-19). (2021). Availabke online at: https://www.cdc.gov/nchs/nvss/vsrr/covid_weekly/index.htm (accessed May 31, 2021)

19. Liu JQ, Xu JW, Sun CY, Wang JN, Wang XT, Chen X, et al. Agestratified analysis of SARS-CoV-2 infection and case fatality rate in China, Italy, and South Korea. Eur Rev Med Pharmacol Sci. (2020) 24:1257578. doi: 10.26355/eurrev_202012_24054

20. Mangia C, Russo A, Civitelli S, Gianicolo EAL. Sex/gender differences in COVID-19 lethality: what the data say, and do not say. Epidemiol Prev. (2020) 44:400-6. doi: 10.19191/EP20.5-6.S2.145

21. Harman K, Verma A, Cook J, Radia T, Zuckerman M, Deep A, et al. Ethnicity and COVID-19 in children with comorbidities. Lancet Child Adolesc Health. (2020) 4:e24-5. doi: 10.1016/S2352-4642(20) 30167-X

22. Alharbi M, Kazzaz YM, Hameed T, Alqanatish J, Alkhalaf H, Alsadoon A, et al. SARS-CoV-2 infection in children, clinical characteristics, diagnostic findings and therapeutic interventions at a tertiary care center in Riyadh, Saudi Arabia. J Infect Public Health. (2021) 14:446-53. doi: 10.1016/j.jiph.2020.12. 034

23. Instituto Nacional de Geografía y Estadística. México en Cifras. (2021). Available online at: https://www.inegi.org.mx/ (accessed May 31, 2021).

24. Salud. Clave Única de Establecimientos de Salud. (2020). Available online at: http://www.dgis.salud.gob.mx/) (accessed May 31, 2021).

25. Ribeiro KB, Ribeiro AF, de Sousa Mascena Veras MA, de Castro MC. Social inequalities and COVID-19 mortality in the city of Saö Paulo, Brazil. Int J Epidemiol. (2021) 10.1093. doi: 10.1093/ije/dyab022

26. Salinas-Escudero G, Carrillo-Vega MF, Granados-Garcia V, MartinezValverde S, Toledano-Toledano F. Garduno-Espinosa J. A survival analysis of COVID-19 in the Mexican population. BMC Public Health. (2020) 20:1616. doi: 10.1186/s12889-020-09721-2

27. Rivas-Ruiz R, Roy-Garcia I, Ureña-Wong K, Aguilar-Iturralde $F$ Vázquez-de Anda G, Gutiérrez-Castrellón P. Factors associated with death in children with COVID-19 in Mexico. Gac Med Mex. (2020) 156:478. doi: 10.24875/GMM.20000478

Conflict of Interest: The authors declare that the research was conducted in the absence of any commercial or financial relationships that could be construed as a potential conflict of interest.

Publisher's Note: All claims expressed in this article are solely those of the authors and do not necessarily represent those of their affiliated organizations, or those of the publisher, the editors and the reviewers. Any product that may be evaluated in this article, or claim that may be made by its manufacturer, is not guaranteed or endorsed by the publisher.

Copyright (c) 2021 Márquez-González, Méndez-Galván, Reyes-López, KlünderKlünder, Jiménez-Juárez, Garduño-Espinosa and Solórzano-Santos. This is an openaccess article distributed under the terms of the Creative Commons Attribution License (CC BY). The use, distribution or reproduction in other forums is permitted, provided the original author(s) and the copyright owner(s) are credited and that the original publication in this journal is cited, in accordance with accepted academic practice. No use, distribution or reproduction is permitted which does not comply with these terms. 